\title{
Implementasi Object Tracking untuk Deteksi Titik Laser Menggunakan Raspberry Pi 4
}

\author{
Florentinus Budi Setyawan, Lies Teddy Galang Ramadhan*, Slamet Riyadi, \\ Leonardus Heru Pratomo \\ Program Studi Elektro, Fakultas Teknik,Universitas Katolik Soegijapranata \\ Jl. Pawiyatan Luhur IV/1 Bendan Dhuwur Semarang 50234, Tlp. 0248441555 \\ *e-mail: liesteddy94@gmail.com
}

(received: 21 Februari 2021,revised: 12 April 2021,accepted: 19 April 2021)

\begin{abstract}
Abstrak
Penelitian ini menyajikan sistem pan-tilt servo yang dapat mengikuti objek yang telah ditentukan. Perlu tercapainya pelacakan yang otomatis dan dapat terpantau melalui monitor. Sistem pada alat ini menggunakan raspberry pi atau komputer kecil, pi camera, pan-tilt servo, laser dan metode template matching. Template matching adalah metode pada pengolahan citra digital untuk menemukan bagianbagian kecil dari gambar yang cocok dengan gambar template. Raspberry pi terhubung pi camera, kamera berfungsi menangkap gambar pada objek setelah disinari titik laser yang digerakkan oleh pan-tilt servo. Menggunakan motor servo yang rasio torsi terhadap beban dan keakuratan. Pengenalan warna atau color recognition dilakukan menggunakan openCV yang terinstall pada raspberry pi. Hasil pada alat ini berupa software yang dapat melakukan object tracking dari penangkapan pi camera dengan jarak objek 2 meter.
\end{abstract}

Kata kunci: camera, raspberri pi,pan-tilt servo, template matching.

\begin{abstract}
This study presents the pan-tilt servo system to follow an object that has been determined.Need to achieve automatic tracking and can be observed through the monitor.The system in this tool uses a raspberry pi or small computer, pi camera, pan-tilt servo, laser and template matching methods.Template matching is a method of processing the digital image to find small parts of the image that matches the template image.Raspberry pi connected to pi camera, the camera functions to capture images of objects after being illuminated by a laser point which is moved by a pan-tilt servo. Using a servo motor which has the ratio of torque to load and accuracy. Color recognition or color recognition is done using openCV installed on the raspberry pi. The result of this tool is software that can perform object tracking from the capture of the pi camera with an object distance of 2 meters.
\end{abstract}

Keywords: camera, raspberri pi,pan-tilt servo, template matching.

\section{Pendahuluan}

Teknologi seperti kamera pada awalnya untuk menangkap gambar saja. Seiring perkembangan zaman, kamera dapat berfungsi sebagai sensor untuk mendeteksi gambar apapun yang ditangkap oleh kamera. Gambar akan diolah oleh perangkat komputer yang terprogram untuk tujuan tersebut, teknologi itu dinamakan computer vision[1].Computer vision memiliki sistem object tracking yaitu sistem yang dapat menentukan posisi dan jarak objek yang bergerak dengan menggunakan kamera.

Software object tracking sangat berguna untuk mengidentifikasi objek dengan menggunakan kamera untuk mempermudah pekerjaan. Banyak di era modern bermunculan software yang dapat membantu mempermudah pekerjaan agar dapat mendefinisikan objek yang dilacak, diantaranya menggunakan gelombang ultrasonic, serta menggunakan metode yang berbeda-beda. Tetapi software dengan menggunakan kamera untuk object tracking masih jarang ditemukan.

Sebuah object trackingatau yang disebut pelacakan objek untuk mendeteksi objek papan besi berlubang yang tersinari oleh titik laser, laser yang digunakan adalah laser yang dapat bergerak 
kekanan-kiri dan keatas-bawah yang dipasang pada pan-tiltservo(bracket motor servo). Sehingga ketika laser digerakkan oleh pan-tiltservo, kamera akan membaca pergerakan titik laser dan kamera dikontrol secara otomatis untuk menjaga posisi titik laser berada pada koordinat lingkaran tengah objek[2].

Dalam proses pelacakan objek, yang pertama harus menentukan objek dalam gambar yang diambil dengan pi camera. Namun karena objek tersebut bergerak, untuk ukuran dan letak objek pada gambar berubah-ubah setiap saat. Untuk mencari objek dengan cepat pada gambar, peneliti menerapkan metode template matching, untuk proses pencarian objek.

Pada penelitian ini menggunakan metode template matching dengan tujuan untuk memudahkan pengguna dalam object tracking.Program dibuat menggunakan Python dan OpenCV untuk menangkap sinar titik laser yang sudah ditentukan warnanya berdasarkan warna RGB (Red, Green, Blue). Setelah warnasinar titik laser pada objek tertangkap oleh kamera maka pan-tiltservo akan terus melacak dan bergerak mengikuti objek yang sudah ditentukan.Tujuan penelitian untuk membuatt software object tracking dengan menggunakan kamera secara real time, sehingga dapat membantu para pengguna untuk mengawasi objek dengan teknologi yang lebih modern dibandingkan hanya menggunakan mata telanjang.Software ini berguna untuk pengawasan tanah longsor, pergeseran tanah yang kurang stabil dan dapat melakukan proses identifikasi jika dikembangkan lebih lanjut.

\section{Tinjauan Literatur}

Victor Wiley dan Thomas Lucas[3], computer vision bekerja menggunakan algoritma dan sensor optik untuk merangsang visualisasi manusia, supaya secara otomatis mengekstrak informasi berharga dari suatu objek. Dibandingkan dengan metode konvensional yang membutuhkan waktu lama dan membutuhkan analisis laboratoriumyang canggih.

Ahmad $\mathrm{F}$ et al [4], melakukan penelitian algoritma sistem pelacakan dengan cara menggabungan algoritma optical flow dan template matching untuk memperkuat pelacakan dan memperkecil galat yang dihasilkan. Sistem telah diujikan pada video permainan sepak bola denganbola sebagai objek yang dilacak. Algoritma optical flow dan template matching digunakan secara bergantian berdasarkan koordinat jarak keduanya yang dihitung menggunakan persamaan jarak Euclidean.

Indra Pramana et al[5], mendesain suatu software program yang dapat melakukan tracking objek, dimana software ini dapat digunakan untuk mengidentifikasikan dan memilah benda yang diinginkan dari background yang tertangkap oleh kamera atau CCTV. Ada beberapa tahapan dalam memproses software tracking objek ini diantaranya yaitu proses pengambilan gambar dari webcam yang aktif untuk database gambar yang dimaksudkan, kemudian cropping gambar untuk memisahkan background dengan objek yang dimaksudkan, dan kemudian proses matching antara image database dengan capture image real time yang dilakukan oleh webcam atau CCTV, sehingga PC dapat membandingkan image database yang tersimpan dengan image yang ditangkap dari webcam yang telah di install.

Vidhyapeeth Rajasthan Neelam Sharma[6], melakukan penelitian tentang gambaran umum template matching.Teknik template matching bersifat fleksibel dan mudah digunakan, dilakukan di bidang seperti image processing, signal processing, kompresi video dan pengenalan pola. Template biasanya digunakan untuk mencetak karakter, mengidentifikasi angka dan objek sederhana lainnya. Ini dapat digunakan untuk mendeteksi tepi dalam gambar di bidang manufaktur sebagai bagian dari kontrol kualitas dan sarana untuk menavigasi robot seluler.

penelitian kali ini membangun sistem kamera untuk pengawasan pergerakan tanah dan mendeteksi adanya gerakan dalam jarak pandang kamera secara otomatis dan memberi tahu penggunanya jika mendeteksi adanya pergerakan melalui monitor. Teknik matchingtidak hanya mengambil ukuran kesamaan tetapi juga menghitung ketidak akuratan antara gambar yeng memperhitungkan perkiraan melalui metrik Mean Squared Error(MSE)[7].

MSE(Mean Squared Error)

$$
=\frac{\sum \sum(\text { Temporary }(u, v)-\operatorname{Target}(u, v)}{\text { Numberofpixels }}
$$




\section{Metode Penelitian}

Pada tahap metode yang digunakan untuk melakukan object tracking adalah metode template matching. Pengambilan metode ini dimulai dari studi pustaka, metode studi pustaka yang dilakukan yakni dengan cara mengkaji jurnal-jurnal yang berkaitan dengan computer vision, template matching dan raspberry pi yang digunakan dalam object tracking pada penelitian ini. Tahap selanjutnya adalah perancangan dan analisa pada alat yang digunakan pada penelitian ini. Tahap yang terakhir adalah pengujian setelah menganalisa hasil data yang didapatkan. Jika hasil data yang didapatkan sudah sesuai maka selanjutnya membuat kesimpulan berdasarkan pengujian yang dilakukan.

\subsection{Perancangan Alat}

Perancangan alat dan bahan ditunjukkan pada Tabel 1.

Tabel 1. Alat dan Bahan yang Digunakan

\begin{tabular}{lll}
\hline \multicolumn{1}{c}{ Alat } & \multicolumn{1}{c}{ Bahan } \\
\hline 1. Raspberry Pi 4 & 1. Operating system raspbian \\
2. Pan-tilt servo bracket & 2. Python IDE \\
3. Pi camera & 3. Open CV \\
4. Laser & 4. Micro SD card $64 \mathrm{~GB}$ \\
5. Kabel connector & & \\
6. Power supply 5V & & \\
7. Kabel HDMI & & \\
8. Monitor & \\
\hline
\end{tabular}

\section{a. Raspberry pi}

Raspberry pi adalah mini computer dengan ukuran single board computer dan memuat processor ARM Cortex, memiliki input dan output GPIO (General Purpose Input Output)[8]. Raspberry pi yang digunakan pada penelitian ini merupakan generasi yang ke 4. Raspberry pi ditunjukkan pada Gambar 1 .

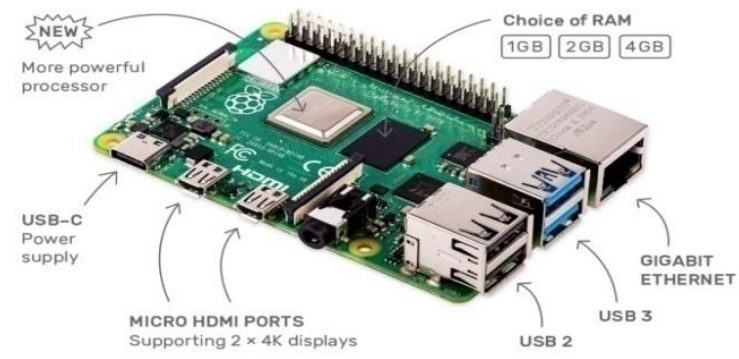

Gambar 1. Raspberry pi 4

\section{b. Pan-Tilt Servo Bracket}

Pada Gambar 2 pan-tiltservo merupakan penggerak laser yang di program untuk menggerakkan titik laser pada obyek yang akan dilacak oleh kamera. Sistem pan-tilt ini digerakkan oleh 2 buah motor servo MG996R bertorsi tinggi dan menggunakan gear logam yang dapat bergerak 180 derajat [9]. 


\section{c. Pi Camera}

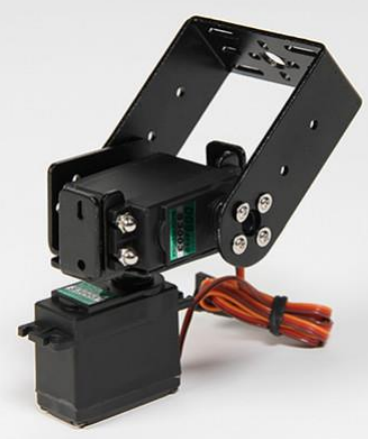

\section{Gambar 2. Pan-tilt Servo Bracket}

Modul pi camera merupakan produk kamera resmi yang diciptakan agar dapat kompatibel dengan perangkat Raspberry Pi. kamera yang kompatibel dengan perangkat komputer akan lebih mudah diprogram karena telah disesuaikan spesifikasinya dan peruntukannya. Pi camera memiliki kemampuan koneksi ke raspberry pi sangat cepat hingga resolusi gambar 1080p (1920x1080x10bpp) pada 30 frames per detik. Pi camera seperti yang terlihat pada Gambar 3.

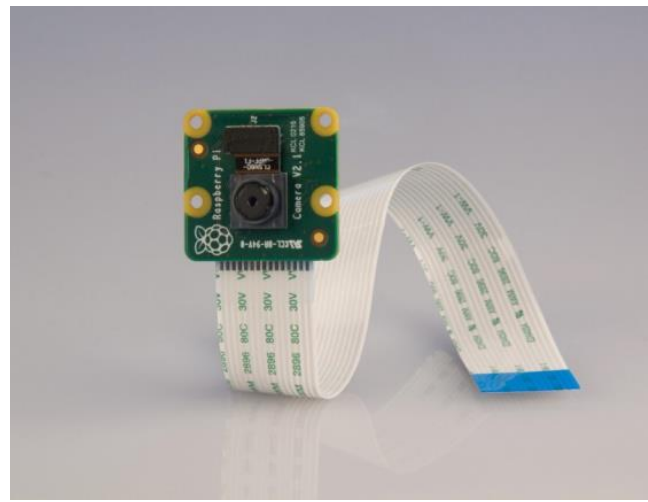

Gambar 3. Modul Pi Camera v2

\section{d. Laser}

Laser adalah singkatan dari bahasa Inggris: Light Amplification by Stimulated Emission of Radiation, merupakan mekanisme suatu alat yang memancarkan radiasi elektromagnetik yang bisa juga diartikan perbesaran intensitas cahaya oleh pancaran terangsang, biasanya dalam bentuk cahaya yang tidak dapat dilihat maupun dapat lihat dengan mata normal, melalui proses pancaran terstimulasi[10]. Pancaran laser biasanya tunggal, memancarkan foton dalam pancaran koheren[11]. Gambar laser ditunjukkan pada Gambar 4.

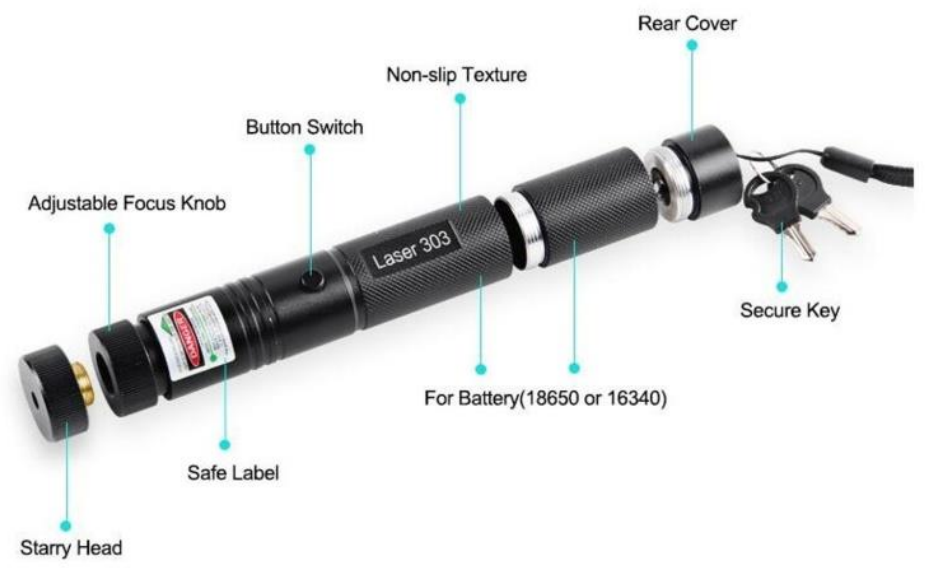

Gambar 4. Laser 


\section{e. Python}

Python adalah bahasa pemrograman yang dapat mengeksekusi sejumlah perintah yang bersamaan secara langsung dengan metode orientasi pada objek yang sudah ditentukan. Python mendukung berbagai paradigma dalam pemrograman yang berorientasi objek, imperantif dan fungsional.Fitur-fitur yang tersedia pada Python yaitu pemrograman dinamis yang dilengkapi dengan manajemen memori otomatis. Tipe Data di Python Variabel menyimpan data yang dilakukan selama program dieksekusi dan isinya dapat diubah oleh operasi - operasi tertentu pada program yang menggunakan variabel tersebut[12].

\section{f. OpenCV}

OpenCV singkatan dari (Open Source ComputerVisionLibrary) adalah sebuah library pemrograman yang digunakan untuk pengolahan citra pada waktu sebenarnya yang diciptakan oleh Intel. OpenCV memiliki banyak fungsionalitas yang dapat membantu dalam pembuatan aplikasi ComputerVision yang lebih mudah dan tidak rumit. OpenCV dapat digunakan dengan bahasa pemrograman yang bermacam-macam seperti Python, Java dan bahasa C[7].

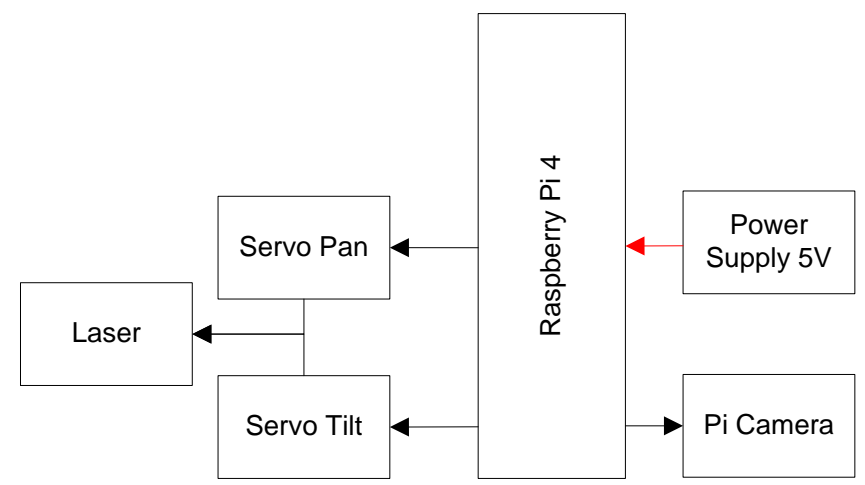

Gambar 5. Diagram Blok Perancangan Alat

Untuk perancanganalatditunjukkanpada blok diagram dalam Gambar 5 terdiri dari dua buah motor servo, laser, raspberry pi 4, komputer dan pi camera. Pi camera mengirimkan informasi citra ke komputer, kemudian dilakukan pengambilan gambar titik laser pada obyek, selanjutnya mengirimkan perintah kontrol ke raspberry pi. Pi camera yang bekerja melakukan pengambilan gambar secara terus menerus dengan selang waktu tertentu, kemudian raspberry pi sebagai komputer akan memproses gambar dengan library Open CV (Open Source Computer Vision Library) menggunakan bahasa pemograman python[13]. Dari informasi yang didapat akan menggerakkan dua buah motor sevo, servo satu untuk pergerakan horizontal (pan) dan servo dua untuk pergerakan vertikal (tilt).

\subsection{Perancangan software}

1 Input citra

Input citra adalah tahap awal untuk mendapatkan citra digital. Tujuan input citra adalah untuk menentukan data yang diperlukan dan memilih metode perekaman citra digital.

\section{$2 \quad$ Pre processing}

Pre processing digunakan untuk penyamaan ukuran matriks yang akan dicocokkan dengan algoritma template matching serta penghilangan noise pada citra.

\section{Grayscale}

Pada proses grayscale masing-masing pixel RGB dari citra diambil nilainya, lalu dilakukan pengambilan mean dari ketiga nilai RGB tersebut, yang nantinya masing-masing nilai $R, G$, dan $B$ akan diinisialisasi dengan nilai rata - ratanya tersebut sehingga tercipta warna keabuabuan dari matriks citra yang telah dilakukan proses grayscale. 


\section{Tresholding}

Tresholding adalah suatu proses yang digunakan untuk menghasilkan citra biner yaitu citra dengan hanya dua warna, yaitu: hitam dan putih. Nilai pixel yang awalnya lebih kecil daripada 127 diinisialisasi dengan nilai pixel 1, sedangkan nilai pixel yang awalnya lebih besar daripada 127 yang berupa background diinisialisasi dengan nilai pixel 0. Untuk pengubahan warna citra menjadi biner, tresholding juga digunakan untuk penghilangan noise yang dapat menggangu hasil dari pengenalan bentuk nantinya[14].

\section{$5 \quad$ Template matching}

Template matching adalah sebuah teknik dalam pengolahan citra digital untuk menemukan bagian-bagian kecil dari gambar yang cocok dengan template gambar. Metode juga sebagai pendeteksian gerakan pada video dimana sistem menetapkan satu gambar sebagai referensi sebelum memulai perhitungan untuk menentukan ada atau tidaknya gerakan.

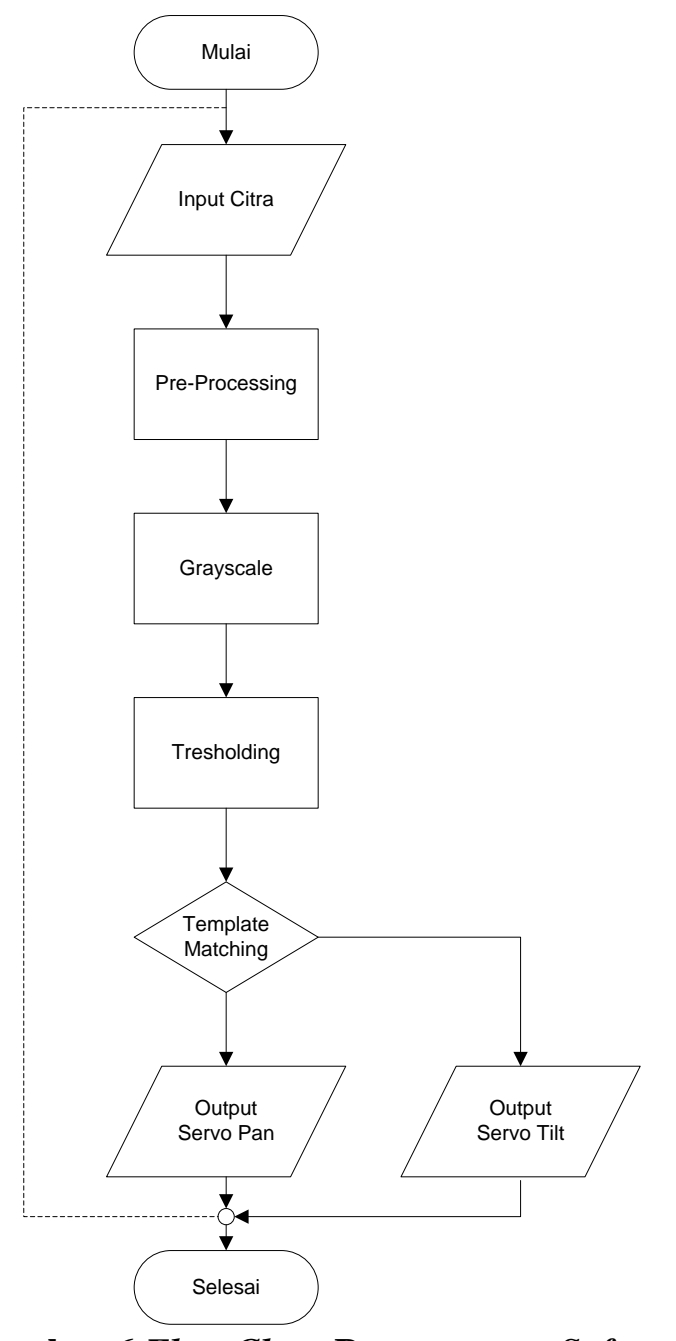

\section{Gambar 6.Flow Chart Perancangan Software}

Gambar 6 merupakan flowchart perancangan softwarecara kerja sistem ini yaitu capture gambar pada objek yang disinari oleh titik laser diproses menggunakan langkah-langkah image processing. Pada proses ini dilakukan tahap untuk mengidentifikasi citra dengan proses template matching, sehingga dapat diidentifikasikan citra dari kamera dan memberikan informasi yang sesuai. Selanjutnya terjadi pencarian di antara template-template yang ada, jika template telah ditemukan maka camera dapat mengenal bentuk tersebut. Setelah kecocokan objek dan template telah terjadi, maka proses pan-tilt servo dapat tracking[15]. 


\section{Hasil dan Pembahasan}

Pengujian alat dilakukan dengan proses observasi dari parameter yang dirancang untuk mengetahui tingkat keakurasian dari metode yang digunakan pada penelitian ini. Hasil yang ditampilkan berupa pengujian pelacakan dan pengukuran pada setiap servo dilakukan untuk pembuktian bahwa hasil alat yang dibuat sesuai dengan rancangan dan teori yang telah disajikan pada bab sebelumnya. Pengambulan data berupa hasil pengendalian laser yang terintegrasi dengan $p i$ camera.

\section{A. Pengujian Pelacakan}

Selanjutnya dilakukan Algoritma pelacakan dengan menggunakan visual studio yang di kirim dengan bahasa pemrograman OPEN $\mathrm{CV}$ library $\mathrm{C}++$. Komputer utama adalah pusat pemrosesan gambar selama proses pelacakan. Jika terjadi kegagalan, ada algoritma lain disebut dengan template matching untuk menangani masalah ini. Algoritma template matchingadalah sebuah teknik dalam pengolahan citra digital untuk menemukan bagian-bagian sederhana dari gambar yang cocok dari template, dengan menggunakan metode ini akan menghitung posisi obyek berdasarkan template obyek yang terakhir terdeteksi. Setelah obyek diidentifikasi maka algoritma akan menghitung kembali pelacakan dan memberikan posisi tengah dari lingkaran obyek ini di setiap frame video kontinu dari kamera. Gambar 7 menunjukkan flowchart cara kerja program.

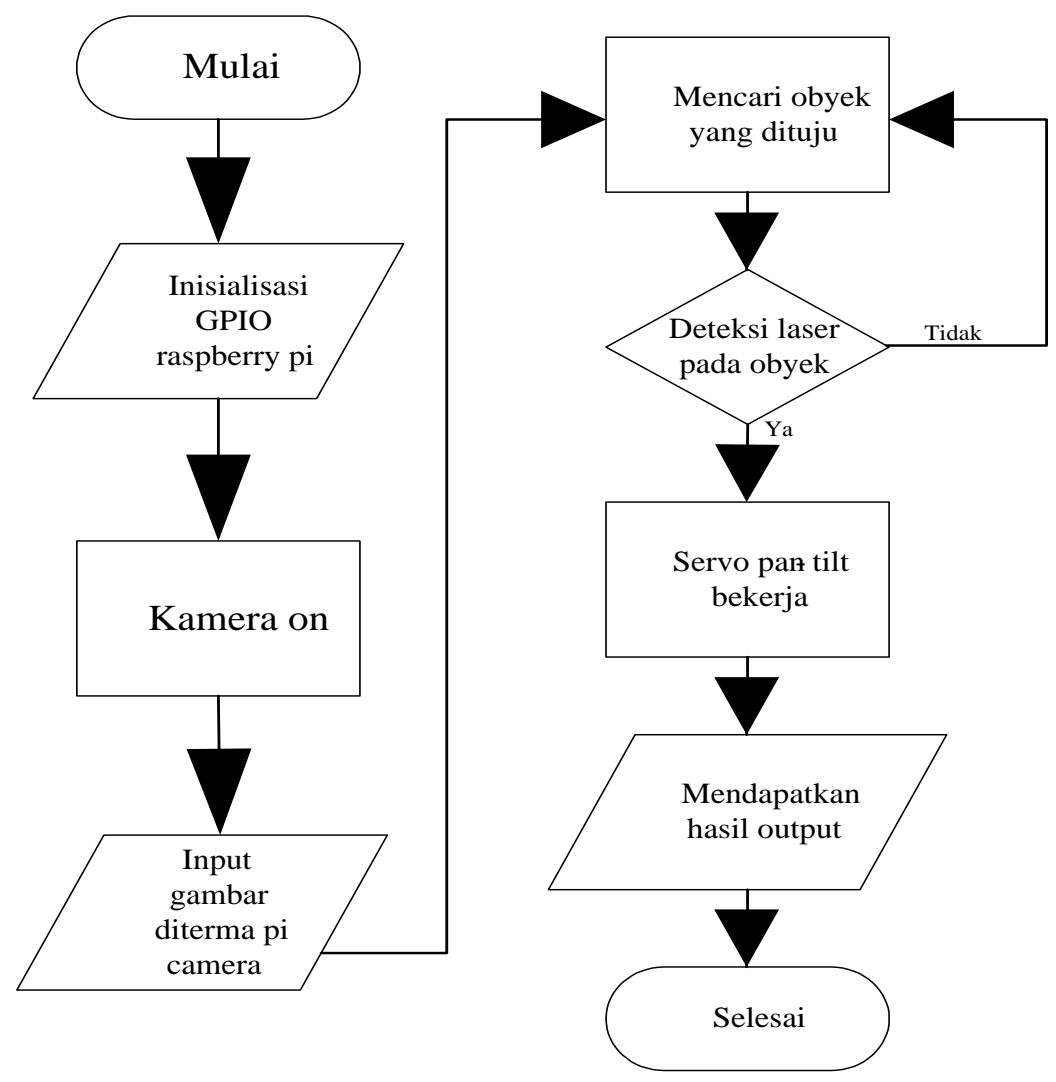

\section{Gambar 7.Flowchart Cara Kerja Program}

Motor servo dilengkapi dengan sistem kontrol yang memberikan umpan balik posisi perputaran motor dari 0 sampai 180 derajat. Disamping itu servo ini memiliki torsi relatif kuat, pemberian PWM pada servo akan membuat bergerak pada posisi tertentu. Frekuensi PWM yang digunakan pada pengontrolan servo selalu $50 \mathrm{~Hz}$ sehingga pulsa dihasilkan setiap $20 \mathrm{~ms} \mathrm{[16].}$

Sistem motor servo terdiri software yang sangat berperan untuk menulis program, meng-compile menjadi kode biner lalu meng-upload kedalam mikrokontrol. Pengujian kinerja tracking dilakukan 
untuk mengetahui stabilitas dan kinerja kontrol motor servo. Dalam situasi ini, identifikasi sistem pertama kali dilakukan untuk menentukan parameter awal. Kemudian kinerja tracking dari setiap servo dievaluasi. Mekanisme kontrol servo digunakan untuk memandu laser agar bergerak disekitar lingkaran obyek yang sudah ditentukan. Hasil ekstrasi fitur berupa koordinat aktual posisi (x,y). Nilai $\mathrm{x}$ dan y selanjutnya menjadi masukkan nilai kontrol proporsional untuk menentukan pergerakan servo dalam laser pan-tilt. Terdapat power supply 5V 3A sebagai power untuk servo pan-tilt. Sedangkan PWM servo dihubungkan pada pin GPIO dan ground pada raspberry pi yang berfungsi sebagai penanda ketika obyek terdeteksi ataupun tidak terdeteksi. Gambar 8 merupakan bentuk fisik dari laser pan-tilt.

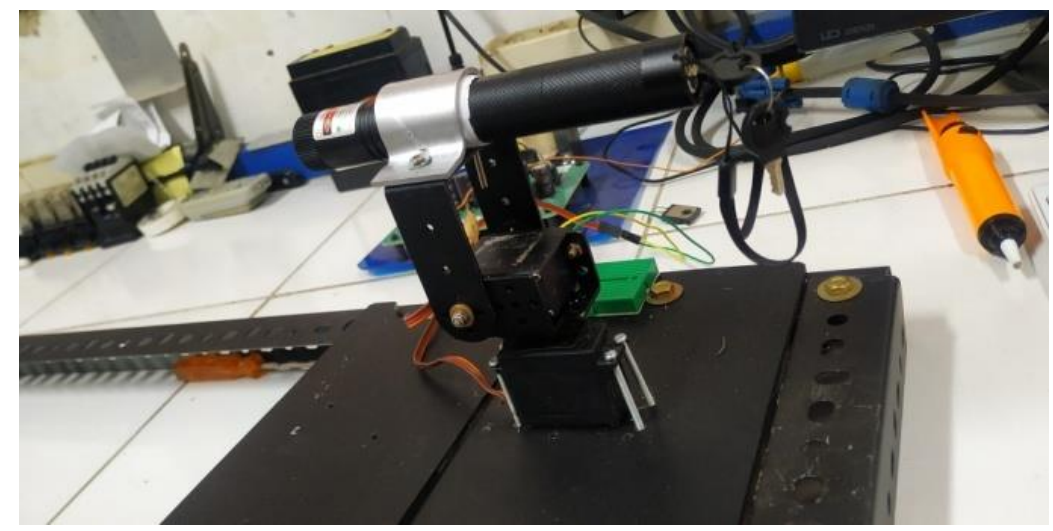

Gambar 8. Bentuk Laser Pan-Tilt

Koordinat data keluaran digunakan untuk mengontrol mekanisme pan-tilt servo untuk berpindah posisi yang diinginkan secara otomatis. Perpindahan koordinat keluaran akan dihitung dan dikirimkan kembali ke sistem masukan untuk dibandingkan dengan pusat obyek sebagai setpoint. Algoritma kontrol akan menghasilkan sinyal PWM untuk pan-tilt servo agar laser berada ditengah lingkaran obyek. Posisi yang diinginkan harus akurat dan cepat dengan menggerakan pan-tilt servo menggunakan algoritma ini untuk semua jenis pengujian. Gambar 9 merupakan parametersoftware dari pelacakan titik laser oleh camera, sedangkan Gambar 10 menunjukkan implementasi alat.

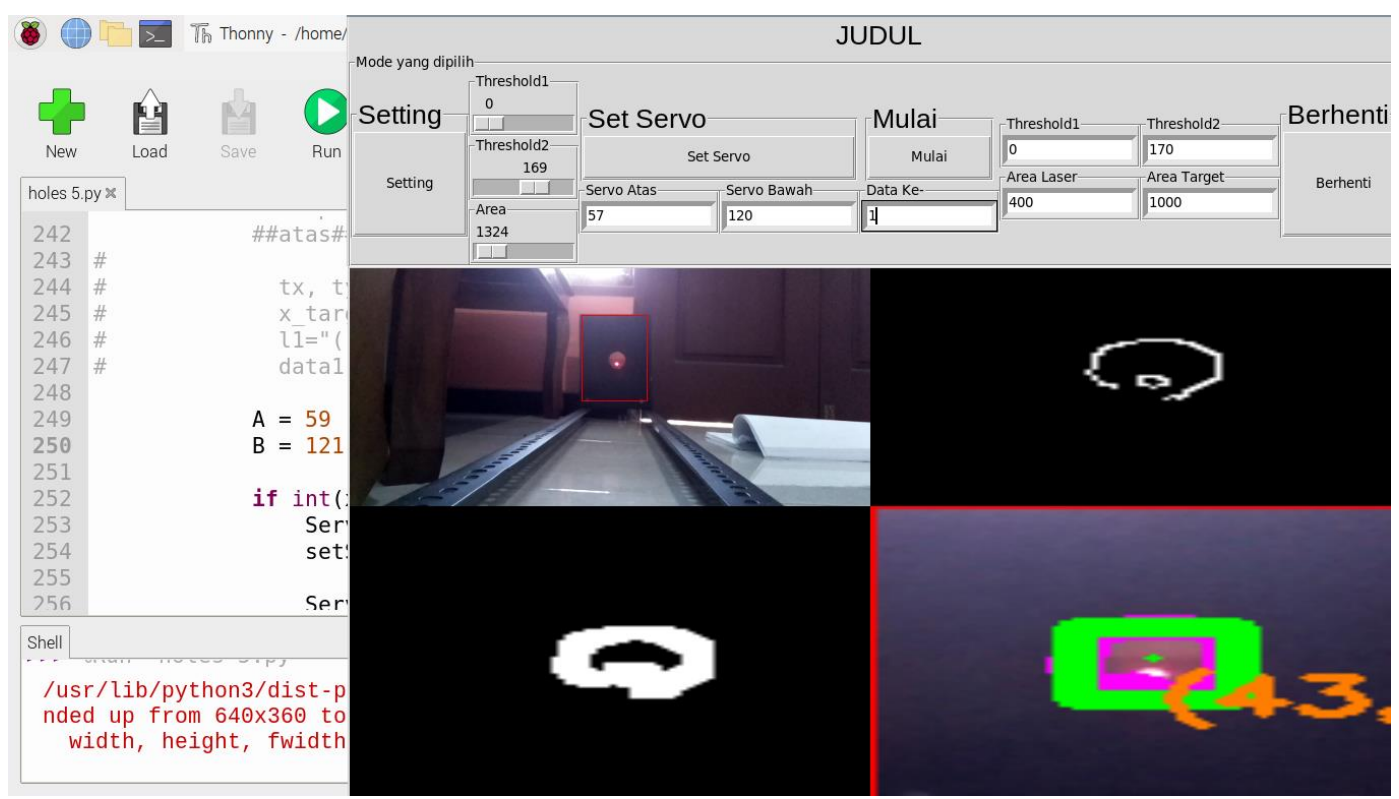

Gambar 9.Parameter Pelacakan Titik Laser oleh Camera 


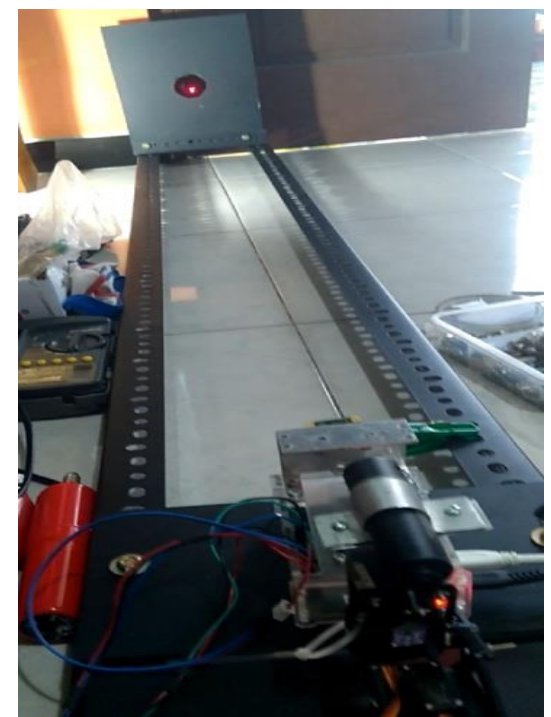

\section{Gambar 10. Implementasi Alat}

Alat tersebut di implementasikan pada media berjarak 2 meter dengan cara menempelkan obyek plat berlubang yang terpasang pada bagian rangka besi, posisi di tengah kedua servo tidak bergerak. Ketika objek digeser kearah atas maupun kebawah maka posisi y pada objek akan berubah dan servo tilt akan bergerak memposisikan agar laser selalu ditengah objek. Dilanjutkan dengan pengujian servo pan yang bergerak kearah kanan dan kearah kiri. Begitu juga dengan cara kerja servo tilt sebelumnya. Ketika objek yang dilacak mulai bergerak kearah kanan maupun kiri, maka servo pan akan mengikuti agar posisi x pada objek selalu ditengah.

\section{B. Pengujian sudut servo pan}

Pada tahap pengujian ini servo pan dilakukan pengujian pergerakan secara horizontal arah kanan dan pergerakan horizontal kearah kiri pada servo. Pada pengujian akan dilakukan pengukuran pergerakan alat dengan sudut yang ditentukan. Pada tabel 2 merupakan pengujian pergerakan alat dengan gerakan pan kanan, pergerakan dari sudut $180^{\circ}$ sampai $18^{\circ}$ dengan selisih setiap sudut $18^{\circ}$. Sedangkan tabel 3 merupakan pengujian pergerakan alat dengan pergerakan pan kiri, dengan pergerakan sudut $18^{\circ}$ sampai $180^{\circ}$ dengan selisih setiap sudut $18^{\circ}$.

Tabel 2.Pengujian Dengan Gerakan Pan Kanan

\begin{tabular}{ccccccc}
\hline No & $\begin{array}{c}\text { Sudut } \\
\text { Sebenarnya }\end{array}$ & I & II & III & IV & V \\
\hline 1 & 180 & 188 & 186 & 185 & 185 & 188 \\
2 & 162 & 165 & 167 & 168 & 166 & 169 \\
3 & 144 & 147 & 148 & 149 & 147 & 151 \\
4 & 126 & 129 & 130 & 130 & 128 & 132 \\
5 & 108 & 111 & 113 & 112 & 111 & 115 \\
6 & 90 & 95 & 97 & 96 & 95 & 99 \\
7 & 72 & 76 & 78 & 78 & 76 & 80 \\
8 & 54 & 56 & 59 & 59 & 58 & 61 \\
9 & 36 & 35 & 39 & 39 & 38 & 41 \\
10 & 18 & 16 & 20 & 20 & 18 & 22 \\
\hline
\end{tabular}


Tabel 3. Pengujian dengan Gerakan Pan Kiri

\begin{tabular}{ccccccc}
\hline No & $\begin{array}{c}\text { Sudut } \\
\text { Sebenarnya }\end{array}$ & I & II & Sudut terukur \\
& 18 & 20 & 21 & 20 & 20 & IVI \\
\hline 1 & 36 & 38 & 39 & 40 & 37 & 40 \\
2 & 54 & 57 & 58 & 58 & 57 & 59 \\
3 & 72 & 76 & 77 & 77 & 76 & 77 \\
4 & 90 & 92 & 94 & 94 & 93 & 95 \\
5 & 108 & 109 & 111 & 110 & 109 & 111 \\
6 & 126 & 128 & 128 & 128 & 128 & 129 \\
7 & 144 & 147 & 147 & 147 & 146 & 148 \\
8 & 162 & 168 & 167 & 166 & 167 & 168 \\
9 & 180 & 188 & 186 & 185 & 185 & 188 \\
10 & 108
\end{tabular}

\section{Pengujian sudut servo tilt}

Pada tahap pengujian ini servo tilt dilakukan pengujian pergerakan secara vertikal arah atas dan pergerakan vertikal kearah bawah pada servo. Pada pengujian akan dilakukan pengukuran pergerakan alat dengan sudut yang ditentukan. Pada tabel 4 merupakan pengujian pergerakan alat dengan gerakan tilt atas, pergerakan dari sudut $180^{\circ}$ sampai $18^{\circ}$ dengan selisih setiap sudut $18^{\circ}$. Sedangkan tabel 5 merupakan pengujian pergerakan alat dengan pergerakan tilt bawah, dengan pergerakan sudut $18^{\circ}$ sampai $180^{\circ}$ dengan selisih setiap sudut $18^{\circ}$.

Tabel 4. Pengujian dengan Gerakan Tilt atas

\begin{tabular}{ccccccc}
\hline No & $\begin{array}{c}\text { Sudut } \\
\text { Sebenarnya }\end{array}$ & I & II & III & IV & V \\
\hline 1 & 180 & 180 & 180 & 180 & 180 & 180 \\
2 & 162 & 165 & 166 & 166 & 166 & 165 \\
3 & 144 & 147 & 147 & 147 & 147 & 147 \\
4 & 126 & 130 & 131 & 130 & 130 & 130 \\
5 & 108 & 112 & 113 & 113 & 113 & 112 \\
6 & 90 & 95 & 96 & 95 & 95 & 95 \\
7 & 72 & 79 & 78 & 78 & 78 & 78 \\
8 & 54 & 59 & 59 & 59 & 59 & 59 \\
9 & 36 & 41 & 40 & 40 & 41 & 40 \\
10 & 18 & 23 & 22 & 22 & 22 & 22 \\
\hline
\end{tabular}

Tabel 5. Pengujian dengan Gerakan Tilt Bawah

\begin{tabular}{ccccccc}
\hline No & $\begin{array}{c}\text { Sudut } \\
\text { Sebenarnya }\end{array}$ & \multicolumn{7}{c}{ I } & II & III & IV & V \\
\hline 1 & 18 & 20 & 19 & 18 & 20 & 19 \\
2 & 36 & 39 & 39 & 36 & 39 & 39 \\
3 & 54 & 58 & 58 & 54 & 58 & 58 \\
4 & 72 & 77 & 77 & 72 & 77 & 77 \\
5 & 90 & 93 & 94 & 90 & 93 & 93 \\
6 & 108 & 111 & 111 & 108 & 111 & 111 \\
7 & 126 & 127 & 128 & 126 & 127 & 127 \\
8 & 144 & 144 & 145 & 144 & 144 & 144 \\
9 & 162 & 162 & 163 & 162 & 162 & 163 \\
10 & 180 & 177 & 179 & 180 & 177 & 178 \\
\hline
\end{tabular}




\section{Kesimpulan}

Dari hasil penelitian yang telah dibuat dapat diambil kesimpulan software akan sangat membantu dalam pengawasan terhadap tanah gerak/longsor. Sistem pan-tiltservo yang diterapkan pada aktuator motor servo dapat melacak pergerakan laser yang terintegrasi pi camera dengan baik sesuai obyek yang diinginkan. Hal ini dibuktikan dengan data yang dihasilkan pada saat pendeteksi laser oleh kamera, yaitu berupa radius dan jarak dinamis antara obyek dan pan-tiltservo. Dalam metode template matching mampu mendeteksi gerakan yang terjadi dalam jarak pandang kamera dengan baik yang dibuktikan pada hasil data servo bahwa pergerakannya stabil.Penggunaan resolusi kamera sangat mempengaruhi jarak obyek, besarnya resolusi ini akan menyebabkan kerja processor dalam pengolahan citra yang semakin berat. Raspberry pi diakses dengan komputer menggunakan IP address sehingga mudah dikontrol asalkan kedua perangkat tersebut terhubung dalam satu jaringan WIFI.

\section{Referensi}

[1] C. Edward, S. Ghanie, and F. B. Setiawan, "Penerapan Sistem Pan-Tilt Camera untuk Deteksi Objek berdasarkan Warna menggunakan Raspberry Pi," vol. 5, pp. 92-96, 2020.

[2] A. Fahriannur and M. Siswanto, "Sistem Tracking Obyek Berbasis Algoritma Optical Flow Menggunakan Kamera Pan-Tilt," pp. 175-178, 2017.

[3] V. Wiley and T. Lucas, "Computer Vision and Image Processing: A Paper Review," Int. J. Artif. Intell. Res., vol. 2, no. 1, p. 22, 2018.

[4] A. Fahriannur, R. Mardiyanto, and M. Siswanto, "Sistem Pelacakan Objek Menggunakan Kombinasi Algoritma Optical Flow dan Template Matching," J. Teknol. dan Sist. Komput., vol. 6, no. 1, pp. 13-17, 2018.

[5] I. Pramana and M. Z. H. Samsono, "Tracking Object Menggunakan Metode Template Matching Berbasis Streo Vision," pp. 2-6, 2011.

[6] B. Vidhyapeeth Rajasthan Neelam Sharma and A. Professor Banasthali Vidhyapeeth Rajasthan, "An Overview of Various Template Matching Methodologies in Image Processing," Int. J. Comput. Appl., vol. 153, no. 10, pp. 975-8887, 2016.

[7] A. Jalil, "Deteksi Gerak Objek Berbasis Pengolahan Citra Menggunakan Metode BinaryImage Comparison," Electro Luceat, vol. 6, no. 1, pp. 109-116, 2020.

[8] Pi Raspberry, "Raspberry Pi 4 Computer," no. June, 2019.

[9] T. Pro, "MG996R High Torque Metal Gear Dual Ball Bearing Servo," Electonic Caldas, no. 6 V, pp. 1-10, 2015.

[10] T. Ou, "Laser interferometric particle imaging measurement image processing dependent on skewed chaotic field," Proc. 2019 IEEE 3rd Inf. Technol. Networking, Electron. Autom. Control Conf. ITNEC 2019, no. Itnec, pp. 2395-2400, 2019.

[11] M. Rawis, "Instrumentasi dan Klasifikasi Laser," J. Inf., vol. 10, pp. 1-16, 2009.

[12] A. N. Syahrudin and T. Kurniawan, "Input Dan Output Pada Bahasa Pemrograman Python," J. Dasar Pemrograman Python STMIK, no. January, pp. 1-7, 2018.

[13] E. W. C. Humani Figur, Adi Kusworo, "Aplikasi Pengolahan Citra pada Raspberry Pi untuk Membedakan Benda Berdasarkan Warna dan Bentuk," vol. 5, no. 4, pp. 157-162, 2016.

[14] J. M. Pasaribu, "Perancangan Sistem Kendali Camera Crane dan 2 Axis Pan-Tilt Head Menggunakan Stick Commander Wireless Remote," p. 110, 2017.

[15] Y. Juqing, W. Dayong, and Z. Weihu, "Precision laser tracking servo control system for moving target position measurement," Optik (Stuttg)., vol. 131, pp. 994-1002, 2017.

[16] O. A. Astra and Y. Mardiana, "Rancang Bangun dan Analisa Pengendali CCTV Berbasis Arduino Menggunakan Smartphone Android," J. Media Infotama, vol. Vol.14 No., no. 1, pp. 39-50, 2018. 